\title{
Deep Learning in Effective English Teaching Strategy of Senior High
}

\author{
Ning Yueying ${ }^{\mathrm{a}}$, Zhu Xiaodong ${ }^{\mathrm{b}}$ \\ School of Foreign Language, Gannan Normal University, Ganzhou, 341000 \\ aningyueying@qq.com, bjsdzxd@163.com
}

Keywords: Deep learning; English of Senior High; Effective Strategy

Abstract: Deep learning, a learning method which deals with higher-order thinking and emphasize learners' ability to understand the learning content and build relationships between new and old knowledge autonomously in order to solve practical problems. Framed by the deep learning theory, conducted literature research method and combining current situation of high school English teaching and learning, this thesis is aimed at studying the effective teaching strategy in English of senior high, improving learners' autonomy, cultivating their lifelong learning ability and achieving effective learning.

\section{Introduction}

Today's society has entered into the age of big data which is with plenty choices of resources and rich information. How to use these information effectively and spend fragmented time to implement deep learning has become the new adventures for educators. A Horizon Report of 2014 (Elementary Education Version) has advocated six tendencies and six challenges, "achieving deep learning” is among them, which reveals that deep learning is up to date and exploring learners' ability to build inner cognitive structure and solve practical problems. China has announced the fundamental requirement of education in a promulgate document "National Medium- and Long-Term Plan for Education Reform and Development”, which is people-centered education. During the stage of Senior High, Students' ability of independent learning, self-improvement and society adaptation should be cultivated, students' curiosity should be stimulated, students' hobbies should be fostered, and the environment of students' critical thinking, free exploring and innovation should be created [1]. The new English curriculum has also emphasized the cultivation of students' ability of learning and lifelong learning, the combination of teaching and learning and the stimulation of students' English learning interest in elementary education. Above documents and reports regarding elementary education have all mentioned the cultivation of students' autonomy learning and lifelong learning, which indicates that deep learning would act as an important role in the learning process. Still, how to implement deep learning in English of Senior High and study the effective strategy has become a question for educators working in foreign language teaching, as a result, this thesis would try to solve the problem with analyzing the deep learning theory and English teaching and Learning in Senior High, hoping to provide some fresh thoughts of deep learning in English of Senior High.

\section{Deep learning}

\subsection{The concept of deep learning}

Deep learning was put forward in a paper named on Qualitative Differences in Learning: IOutcome and Process [2], written by two American scholars, Ference Marton and Roger Saljoa, 
mentioning its concept and providing comprehensive description. However, the first person who advocated deep learning in China is Professor $\mathrm{Li}$, and his explanation of the term is that deep learning is one kind of learning which based on the understandable level, learners are capable of studying new concept and facts in a critical way and consolidate them into the primary cognitive structure, relate numerous thoughts and transfer the existing knowledge to new context and making decisions and solve problem [3]. Deep learning is on the basis of primary knowledge and a meta-cognitive process of re-constructing knowledge and cognitive strategy, which is the cognition of learning process and having the transfer of knowledge as a target to solve practical problems in learning process. Different from surface learning, learner who participated in deep learning are of strong initiatives, with a purpose to rebuild the knowledge structure and provide solutions for new problems and acquire knowledge that are cohesive and lasting, and more importantly, to achieve higher order learning activities with self-adjusting learning strategies. In the meantime, compared with deep learning, surface learning is the repetition and memorization of knowledge, which is lack of the elaborate processing of knowledge and a passive learning. Surface learning and deep learning are an interactive process, in other words, deep learning is not built until it go through the surface learning level, in which learners will be able to criticize and understand the knowledge autonomously, and construct, integrate, transfer and apply the knowledge.

\subsection{The characteristics of deep learning}

In terms of ways of memorization, knowledge system, focusing point, degree of engagement, reflection status, transfer ability, level of thinking and learning motivation, we are comparing the differences between surface learning and deep learning, in order to summarize the characteristics of deep learning.

The comparison of surface learning and deep learning [4]

\begin{tabular}{|c|c|c|}
\hline & deep learning & surface learning \\
\hline Ways of memorization & $\begin{array}{l}\text { Emphasize the memorization } \\
\text { through understanding }\end{array}$ & Rote memory \\
\hline Knowledge system & $\begin{array}{l}\text { Build connection between new } \\
\text { and old knowledge, and master } \\
\text { non-structured knowledge like } \\
\text { complex concepts and in-depth } \\
\text { knowledge, etc. }\end{array}$ & $\begin{array}{l}\text { Learning fragmented, isolated } \\
\text { knowledge which is structured, } \\
\text { like concepts and principles, } \\
\text { etc. }\end{array}$ \\
\hline Focusing point & $\begin{array}{l}\text { Focusing on core concept of } \\
\text { solving a problem }\end{array}$ & $\begin{array}{l}\text { Focusing on formulas and } \\
\text { external cues when solving a } \\
\text { problem }\end{array}$ \\
\hline Degree of engagement & Autonomy learning & Passive learning \\
\hline Reflection status & $\begin{array}{l}\text { Deepen understanding } \\
\text { gradually, and think and reflect } \\
\text { critically, }\end{array}$ & $\begin{array}{l}\text { Lack of reflection during } \\
\text { learning process }\end{array}$ \\
\hline Transfer ability & $\begin{array}{l}\text { Capable of applying learned } \\
\text { knowledge to practice }\end{array}$ & $\begin{array}{l}\text { Not capable of apply learned } \\
\text { knowledge flexibly }\end{array}$ \\
\hline Level of thinking & Higher-order thinking & Lower-order thinking \\
\hline Learning motivation & Self-needs & External pressure \\
\hline
\end{tabular}

After analyzing the concept of deep learning and comparing the difference between surface learning and deep learning, the characteristics are listed as follows: 
Deep learning emphasizes learners' autonomy. It could be seen when learner are engaging their autonomy into learning, and thinking critically and deepen understanding or reflecting the practical problems. Deep learning learners would also focus on the core concept and transfer what they have learnt flexibly.

Deep learning optimizes the construction and integration of knowledge. In terms of knowledge system, deep learning learners have a good command of building relations between old and primary knowledge, mastering non-structured knowledge like complex concepts and deep knowledge. They make use of the knowledge and combine them to become a solid building. Learners who have gone through deep learning will have a more complete knowledge system.

Deep learning cultivates learners' lifelong learning ability. Deep learning is relying on higher-order thinking, which will foster students' ability to have autonomy in learning. In terms of learning motivations, students are learning for their own needs and learning knowledge and skills autonomously.

\section{The current situation of English teaching and learning in Senior High}

According to the current situation of English teaching and learning in Senior High, and problems occurring during English learning process, this part would try to find the problem and provide support and help in seeking the effective teaching strategy in English teaching of Senior High.

\subsection{The characteristics of English in Senior High}

The characteristics of English in high school can be analyzed from the following aspects, namely, they are listening comprehension, vocabulary, grammar, reading comprehension and writing. In high school English learning, it is not hard to notice that listening comprehension has deepened its content from surface information to deep one, and in the meantime, the increasing vocabulary has expanded from 3,000 to 4,500. Grammar learning has become more systematical, which has extended into attributive clause, noun clause, adverbial clause, non-finite verb and so on. Meanwhile, the degree of reading comprehension has added and extended into a wide range of material selection. Last but not least, writing becomes more and more difficult and requires students to express their ideas and opinions in an explicit way and master several writing styles [5].

\subsection{Learners' performance in traditional language teaching classroom}

According to relevant data, learners are tending to consider English as in irrelevant subject when studying under the traditional language learning. However, learners are paying less attention to procedural knowledge and self-reflection after class when training the four basic language skills. What the learners do is repeating and imitating what the teachers do and learning in a mechanical way.

\subsection{Grades-oriented English Teaching}

In actual English teaching of Senior High classroom, teachers usually conduct teaching activities which helps students improve their grades rather than considering the varieties and differences of students'. Under this circumstance, learners are not achieving deep learning, for they are following teachers' steps and not intending to form their own learning styles.

\subsection{Learning strategy analysis based on the new English curriculum}

The new English curriculum are categorizing the foreign language learning strategy into several parts, namely, they are the cognitive strategy, monitoring strategy, communication strategy, and resource strategy, etc. Cognitive strategy are the steps and methods for students to accomplish specific learning activities, monitoring strategy is a kind of strategy when students plan, implement, reflect, assess and adjust learning process and outcomes. Communication strategy is a collection of 
strategy used when students are fighting for more communication chances, sustain and improve their communication. And resource strategy is a kind of strategy which students make use of the multimedia to start learning and applying English learning [6]. Several findings show that students in Senior High are not able to use the above foreign language learning strategy, most of the students are not focusing on the feedback and assessment after class and not able to use the resource strategy to create a better environment for English learning, as a result, they are not forming a self-realization of mastering the principles and methods in English learning.

\section{Study on Effective teaching strategy of English in Senior High}

\subsection{Setting effective teaching objective}

Effective teaching objectives are able to direct the language class into a well-organized one, which serve as an anticipated learning outcome of implemented high school English teaching activities. All teaching activities should be surrounded effective teaching objectives and taken deep learning as consideration. During the teaching and learning process, teachers' role is to clarify the teaching objectives based on the students' primary knowledge level, current cognitive level, the difficulty of teaching material and so on, in order to achieve deep learning. Take high school English textbook as an instance, in Senior High English for China, module one, unit 1 Friendship, I designed the following teaching objectives with the standard of new English curriculum and current students' level: firstly, the aspect of knowledge and skill, students will be able to discuss topics relating to friendship, understand the essence of friendship and learn how to get along with friends, master the words and grammatical rules of this unit and language skills relating to friendship; secondly, procedure and method, students will be able to use certain reading skills like skimming and scanning to understand the content of the text and appreciate the literature work of friendship; thirdly, emotional attitude, students will be able to realize the importance of friendship and learn how to maintain friendship. Based on the above teaching objectives, students' learning is conducted in deep learning but starting with surface learning.

\subsection{Improving learning autonomy}

According to the new English curriculum on students' outlook and deep learning theory, students' learning of English in Senior High should be able to construct and integrate their own knowledge system, deepen understanding of declarative knowledge and procedural knowledge, improve abilities to learn and cultivate lifelong learning habit. The ways to improve learners' autonomy could be implemented in the following aspects, such as cooperative inquiry method, multi-media, learning strategy, inner learning motivation and so on. When using cooperative inquiry method, students will be divided into groups to following teachers' steps to achieve deep learning. Students will also make use of multi-media to strengthen their interest through English movies, songs and novels. Students' autonomy could be improved with the selection of learning strategy, like cognitive strategy, meta-cognitive strategy and monitoring strategy, in order to monitor and adjust self-learning process and learning effect and achieve deep learning with their own styles. In the meantime, improving students' autonomy also relies on inner learning motivation, deep learning will not be achieve unless learners' motivation comes from the inside.

\subsection{Deep Learning with Authenticity}

The authenticity is the only condition which can achieve students' deep learning. During authentic learning environment, deep learning learners need to solve problems with knowledge structure. Even though the primary knowledge could help learners provide scaffolding, reflections is still needed to master deep level knowledge and complex concept, creating authenticity to achieve deep learning for students [7]. For example, teachers can pose questions related to the topic to make students experience the authenticity. 


\subsection{Teaching assessment and reflection}

Assessment and reflection are specific standards for examining deep learning, which deals with higher order think. Good assessment and reflection will provide feedback immediately and serves as adjustment and monitoring for students' learning process and outcomes. The assessment has two forms, process assessment and procedural assessment. Students would be more focusing on the procedural assessment when learning in deep, which shows that students' knowledge have been deepened, critical thinking has formed and self-reflection has been given. Only in this way would students' deep learning be achieved and appropriative learning styles are created.

\section{Conclusion}

Deep learning, a learning mode with criticalness and emphasis of knowledge construction, integration, transfer and application, requires that learners should be able to understand the learning objectives, become interested in learning autonomously, cultivate deep learning habit, learn in authentic environment and assess learning outcomes and give feedbacks. As a result, teachers and students need to distinguish the difference between surface learning and deep learning, realizing that deep learning is beyond the surface level and fostering students' lifelong learning ability. This thesis provides some ideas about effective teaching strategy of English in Senior High, which might be the focusing point for the further foreign language teaching.

\section{References}

[1] National Medium- and Long-Term Plan for Education Reform and Development, CPC Central Committee and the State Council, 2008.8

[2] Marton F, Saljo R. On qualitative differences in learning: I- outcome and process , J. British Journal of Educational Psychology, 1976, (46): 4-11.

[3] He Ling, Li Jiahou, Promoting Students’ Deep Learning, J. Teaching and Learning of Computer, 2005,(5):29-30.

[4] Zhang Hao, Wu XIujuan, Study on the Meaning and Cognitive Theory of Deep Learning, J. China Educational Technology, 2012, (10): 7-11

[5] Zheng Pingli, The Characteristics of English in Senior High and Its Learning Method, J. Lin District Education, 2013(12):73-73.

[6]National English Curriculum Standards for general High School, R. The Ministry of Education, Beijing, 2003:18-21.

[7] Yan Naisheng, Classroom Situations under the Perspective of Deep Learning, J. Research on the development of Education, 2013,(12): 76-79.

[8] Zhou Hongjun, on Students’ Autonomy in English Teaching, J. Teaching Monthly, 2011, (12): 14-17

[9] Zhang Hao, Wu XIujuan, Wang Jing, Study on the Evaluation Theoretical Structure Building of Deep Learning, J. China Educational Technology, 2014,(7):51-55. 